\title{
Renal hypouricemia caused by novel compound heterozygous mutations in the SLC22A12 gene: a case report with literature review
}

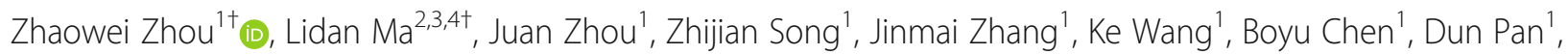
Zhiqiang Li, ${ }^{1,5}$, Changgui $\mathrm{Li}^{2,3,4,6^{*}}$ and Yongyong Shi ${ }^{1,2,3,5^{*}}$

\begin{abstract}
Background: Renal hypouricemia (RHUC) is a heterogeneous genetic disorder that is characterized by decreased serum uric acid concentration and increased fractional excretion of uric acid. Previous reports have revealed many functional mutations in two urate transporter genes, SLC22A12 and/or SLC2A9, to be the causative genetic factors of this disorder. However, there are still unresolved patients, suggesting the existence of other causal genes or new mutations. Here, we report an RHUC patient with novel compound heterozygous mutations in the SLC22A12 gene.

Case presentation: A 27-year-old female presenting with recurrent hypouricemia during routine checkups was referred to our hospital. After obtaining the patient's consent, both the patient and her healthy parents were analyzed using whole-exome sequencing (WES) and Sanger sequencing to discover and validate causal mutations, respectively. The prioritization protocol of WES screened out two mutations of c.269G > A/p.R90H and c.1289_1290insGG/p.M430fsX466, which are both located in the SLC22A12 gene, in the patient. Sanger sequencing further confirmed that the patient's heterozygous c.269G > A/p.R90H mutation, which has been reported previously, derived from her mother, and the heterozygous c.1289_1290insGG/p.M430fsX466 mutation, which was found for the first time, derived from her father. p.R90H, which is highly conserved among different species, may decrease the stability of this domain and was considered to be almost damaging in silicon analysis. p.M430fs X466 lacks the last three transmembrane domains, including the tripeptide motif $(S / T) X \Phi(X=$ any amino acid and $\Phi=$ hydrophobic residue), at the $C$-terminal, which interact with scaffolding protein PDZK1 and thus will possibly lead to weak functioning of urate transport through the disruption of the "transporter complex" that is formed by URAT1 and PDZK1.
\end{abstract}

Conclusions: We report a Chinese patient with RHUC, which was caused by compound heterozygous mutations of the SLC22A12 gene, using WES and Sanger sequencing for the first time. Mutation-induced structural instability or malfunction of the urate transporter complex may be the main mechanisms for this hereditary disorder.

Keywords: Hypouricemia, Chinese, SLC22A12, Mutation, Whole-exome sequencing

\footnotetext{
* Correspondence: lichanggui@medmail.com.cn; shiyongyong@gmail.com

'Zhaowei Zhou and Lidan Ma contributed equally to this work.

${ }^{2}$ Shandong Gout Clinical Medical Center, Qingdao 266003, People's Republic of China

${ }^{1}$ Bio-X Institutes, Key Laboratory for the Genetics of Developmental and

Neuropsychiatric Disorders (Ministry of Education), Shanghai Jiao Tong

University, No. 1954 Huashan Road, Shanghai 200030, People's Republic of

China

Full list of author information is available at the end of the article
}

(c) The Author(s). 2018 Open Access This article is distributed under the terms of the Creative Commons Attribution 4.0 International License (http://creativecommons.org/licenses/by/4.0/), which permits unrestricted use, distribution, and reproduction in any medium, provided you give appropriate credit to the original author(s) and the source, provide a link to the Creative Commons license, and indicate if changes were made. The Creative Commons Public Domain Dedication waiver (http://creativecommons.org/publicdomain/zero/1.0/) applies to the data made available in this article, unless otherwise stated. 


\section{Background}

Renal hypouricemia (RHUC) is a relatively rare heterogeneous genetic disorder that is characterized by decreased serum uric acid concentration $(\mathrm{SUA}<2.0 \mathrm{mg} / \mathrm{dl}$ ) and increased fractional excretion of uric acid (FEUA $>10 \%$ ), which itself does not cause evident discomfort, but it may lead to severe complications, such as urolithiasis and acute kidney injury (AKI), after strenuous exercise in some patients [1]. The confirmation diagnosis and specific subtyping are determined by molecular analysis of the SLC22A12 gene (encoding uric acid transporter 1, URAT1) [2] and the SLC2A9 gene (encoding glucose transporter member 9, GLUT9) [3]. URAT1 was the first identified renal urateanion transporter that is mainly expressed in the apical side of the proximal tubule, and three homozygous lossof-function mutations were confirmed to cause idiopathic renal hypouricemia (classified as RHUC1) [2]. Until now, dozens of mutations in the SLC22A12 gene (24 missense mutations [2, 4-12], 2 nonsense mutations [2, 4], 3 small deletions [4, 11, 12], 1 splice-site mutation [4], and 1 gross deletion mutation [5]) have been detected and functionally characterized in more than 150 RHUC patients from all over the world, but mainly in Japan. GLUT9 is a voltagedriven urate efflux transporter from tubular cells into blood and the interstitium and its loss-of-function mutation was first found in a non-SLC22A12 defect RHUC patient (classified as RHUC2) [3]. The detected mutations in the SLC2A9 gene were fewer but more pathogenic in inducing severe manifestations compared with that of SLC22A12. Genome-wide association studies (GWASs) aim to identify disease/phenotype-associated susceptibility genes and multiple GWASs have correspondingly confirmed a strong correlation of both SLC2A9 and SLC22A12 with SUA concentration [10, 13-20], providing further evidence of their causative role in RHUC. In addition, many transporters have been postulated to be involved with urate flux pathways in the renal proximal tubule: OAT4/SLC22A11 and OAT10/SLC22A13 function as apical urate reabsorption transporters in the exchange of organic anions; OAT1/SLC22A6, OAT2/SLC22A7, and OAT3/SLC22A8 are located in the basolateral membrane and translocate urate from the interstitium into the tubule coupled with $\alpha$-ketoglutarate $(\alpha-K G)$ or other unknown anions exiting, and then urate is secreted by apical transporters of MRP4/ABCC4, ABCG2, NPT1/SLC17A1, and NPT4/SLC17A3 [21]. Further, a scaffolding protein of PDZ domain containing 1 (PDZK1) was identified as modulating urate transport by interacting with a complex of URAT1, OAT4, NPT1, and ABCG2 [22, 23]. Previous reports on RHUC mainly focused on the molecular analysis of the well-confirmed causal genes SLC22A12 and/or $S L C 2 A 9$, and there was still a handful of patients with an absence of defects $[4,6,7,24,25]$, indicating the complexity of urate homeostasis and the existence of other causal genes and mutations. There is no consensus on the treatment for RHUC and outcomes may be severe [26], which raises the urgency of an early and accurate diagnosis for the early prevention of urolithiasis and AKI. Our study, for the first time, comprehensively applied whole-exome sequencing (WES) technology and Sanger sequencing to identify the causal genes and mutations in an autosomal recessive family of an RHUC daughter and healthy parents.

\section{Case presentation \\ Case report}

The index patient was a 27-year-old Chinese Han female with non consanguineous parents. She was accidentally noted to have a low SUA level on two occasions (SUA $=0.52 \mathrm{mg} / \mathrm{dl}$ and $0.45 \mathrm{mg} / \mathrm{dl}$ ) in her routine check-up in the local hospital. She was asymptomatic and had no other discomfort, such as joint pain, loin pain, hematuria, urine foam, nausea, vomiting, anorexia, or diarrhea. No special treatment was recommended. She was recently admitted into the metabolism division, the Affiliated Hospital of Qingdao University due to the repeated detection of hypouricemia; thorough laboratory and imaging examinations were carried out. Biochemical tests confirmed the diagnosis of hypouricemia $(\mathrm{SUA}=0.33 \mathrm{mg} / \mathrm{dl}$ ) with hyperuricosuria $(\mathrm{FEUA}=50 \%)$. The current reference ranges for SUA used in our laboratory department are $3.5-7.0 \mathrm{mg} / \mathrm{dL}$ in males and $2.5-6.0 \mathrm{mg} / \mathrm{dL}$ in females. Meanwhile, the reference range for FEUA is $4-10 \%$, irrespective of gender. Other biomedical findings were within normal range or negative. No kidney stones were found by local ultrasound. Acquired hypouricemia resulting from Fanconi syndrome and other clinical disorders were excluded. Both parents of the patient are alive and healthy, with no evident medical history, such as urolithiasis and AKI. The SUA concentration in the father was $3.68 \mathrm{mg} / \mathrm{dl}$, which was within the lower-normal range, and the mother was $4.35 \mathrm{mg} /$ $\mathrm{dl}$, which was within the fully normal range. A FEUA test was not performed in both parents because they refused to have it done. The patient does not have any siblings. There is no history of hereditary diseases and there are no specific physical abnormalities. In addition, the patient stated she was a vegetarian who did not favor meat. Based on the overall information, we concluded that the patient had idiopathic RHUC. Clinical data are shown in Table 1. Pharmacologic therapy was not administered due to the absence of significant clinical manifestations and the lack of guidelines for RHUC management. However, several medical orders were required in order to inhibit the urate overproduction and prevent the incidence of adverse events: the patient was instructed to drink plenty of water and consume a 
Table 1 Clinical data and confirmed SLC22A12 mutations in patient and both parents

\begin{tabular}{|c|c|c|c|c|c|c|c|c|}
\hline \multirow[t]{2}{*}{ Individuals } & \multirow[t]{2}{*}{ Gender } & \multirow[t]{2}{*}{ Age } & \multirow{2}{*}{$\begin{array}{l}\text { SUA } \\
(\mathrm{mg} / \mathrm{dl})\end{array}$} & \multirow[t]{2}{*}{ FEUA(\%) } & \multirow{2}{*}{$\begin{array}{l}\text { Clinical } \\
\text { symptoms }\end{array}$} & \multicolumn{2}{|l|}{ SLC22A12 mutations } & \multirow[t]{2}{*}{ State } \\
\hline & & & & & & nucleotide & amino acid & \\
\hline Patient & Female & $27 y$ & 0.33 & 50 & - & c.269G > A/c.1289_1290insGG & p.R90H/p.M430fsX466 & $\begin{array}{l}\text { compound } \\
\text { heterozygote }\end{array}$ \\
\hline Father & Male & NA & 3.68 & NA & - & c.1289_1290insGG/WT & p.M430fsX466/WT & heterozygote \\
\hline mother & Female & NA & 4.35 & NA & - & c.269G > A/WT & $\mathrm{p} . \mathrm{R} 90 \mathrm{H} / \mathrm{WT}$ & heterozygote \\
\hline
\end{tabular}

- denotes negative, NA denotes not available

low purine diet, avoid engaging in strenuous exercise, alkalize urine with sodium bicarbonate continuously and moderately, and monitor renal function regularly via laboratory and imaging examinations during subsequent outpatient follow-up. The case reports (CARE) guidelines were followed.

\section{Genomic DNA preparation}

The patient and both of her parents were recruited for this study. Peripheral blood samples were collected upon the patient signing the relevant informed consent. Genomic DNA was subsequently extracted using LifeFeng Genomic DNA Purification Kit (Lifefeng Biotech Co., Ltd., Shanghai, China) and then quantified for concentration and purity evaluation by a NanoDrop 1000 Spectrophotometer (Thermo Scientific, USA). All of the samples were within the reference range (doublestranded DNA concentration: $>20 \mathrm{ng} / \mathrm{ul}, 260 / 280$ : $>1.8$, 260/230: > 2.0) that satisfied the requirements of the genomic analysis.

The study was approved by the Ethics Committee of Shanghai Jiao Tong University and the Affiliated Hospital of Qingdao University, and it was conducted in accordance with the principles of the Declaration of Helsinki.

\section{WES}

An initiation of $0.2 \mu \mathrm{g}$ genomic DNA was subjected to WES. Genomic DNA was sheared into fragments of $150 \mathrm{bp}$ in size by a Covaris ${ }^{\text {Tu }}$ S2 Ultrasonicator System (Covaris, Woburn, MA, USA) and the product was ligated to paired-end adapters containing Illuminaspecific indexes using a SureSelect XT Library Prep Kit ILM (Agilent Technologies, Santa Clara, CA). The resulting product was amplified by ligation-mediated polymerase chain reaction (LM-PCR). The adapter-ligated DNA library was enriched and captured with a SureSelect Target Enrichment Kit Box 1 (Agilent Technologies, Santa Clara, CA). Each well-constructed library was then sequenced as 150 bp paired-end reads on an Illumina HiSeq 2500 platform (Illumina, San Diego, California, USA), at the coverage depth of 50x. Briefly, crude sequencing data were checked for quality control by FastQC v 0.11 .2 (http://www.bioinformatics.babraham.ac.uk/projects/fastqc/) and then trimmed by Trimmomatic v 0.30 to exclude unqualified reads. The resulting clean reads were aligned to NCBI build GRCh37/ hg19 by Burrows-Wheeler Aligner (BWA) v 0.7.7. The aligned reads were processed to remove the duplications by Picard v 1.110. Then, local realignment and annotation with RefSeq genes, dbSNP 138, and 1000 Genomes Project were performed by Genome Analysis Toolkit (GATK) v 2.8-1 and Annovar software [27], respectively.

\section{Sanger sequencing}

Candidate mutations of interest were further validated by PCR amplification and direct Sanger sequencing. PCR primers were designed using a primer designing tool (http://www.ncbi.nlm.nih.gov/tools/primer-blast/index.cgi? LINK_LOC=NcbiHomeAd) and they were ordered from Shanghai Generay Biotech Co., Ltd., Shanghai, China. Primer sequences are listed in Table 2. PCR amplification was performed on a GeneAmp PCR System 9700 (Applied Biosystems, Foster City, CA) with 2X Taq PCR Master Mix (Lifefeng Biotech Co., Ltd., Shanghai, China), and the product was loaded on ABI 3100 instruments (Applied Biosystems, Foster City, CA) at Shanghai Jieli Biotechnology Co., Ltd. for Sanger sequencing.

\section{Causality predictions of identified mutations}

Annotations with SIFT, Polyphen-2, LRT, and MutationTaster by Annovar, were performed to evaluate the mutation pathogenicity. Since the crystal structure has not been available, TMpred online software and Pymol 2.0 , a free and user-friendly molecular visualization tool, were used to predict the secondary functional domains of the URAT1 protein and its 3-D image, respectively.

Table 2 Primer sequence for SLC22A12 mutations

\begin{tabular}{lll}
\hline $\begin{array}{l}\text { Primer } \\
\text { name }\end{array}$ & Forward primer sequence & Reverse primer sequence \\
\hline $\begin{array}{l}269 \\
\text { primer }\end{array}$ & TCCAGGTTCTCCAGACGATG & TCCCAGGACTGGACCTTTGAG \\
$\begin{array}{l}1289 \\
\text { primer }\end{array}$ & AAACGGGGTCAAGAAGGACTC & CACAAGAGGGAGATGCATGA \\
\hline
\end{tabular}




\section{Mutations analysis}

To screen out the genetic mutations leading to RHUC, WES was applied in genomic DNA from the RHUC patient and both of her parents. On average, the total number of bases in the reads was $4520 \mathrm{Mb}$ and the ratio of bases having a phred score of greater than 30 (Q30) reached up to $94 \%$. The detailed outputs are shown in Table 3.

According to an assumed inheritance of the autosomal recessive mode for this disease, we first analyzed the putative genetic mutations homozygous in the patient and heterozygous in both of the parents. Seeking functional variants, we filtered out those referred to as either unknown or synonymous. Focusing on rare variants, we sought for those having frequencies $<0.01$ or unknown in 6500 Exome Sequencing Project database. Then, we excluded those present in the in-house exome sequence data obtained from 16 normal unrelated individuals, and finally, 29 variants were retained (see Sheet 1 in Additional file 1). Unfortunately, none of the variants in the genes were functionally candidates for purine/ uric acid metabolism and excretion. Next, we analyzed the putative causal mutations present in the patient but not present in the parents based on the prioritization strategy mentioned above. A total of 521 suspicious mutations were screened out (see Sheet 2 in Additional file 1). In terms of the known candidate genes related to purine/uric acid metabolism and excretion, we finally chose the mutations located in the SLC22A12 gene for further Sanger sequencing.

Sanger sequencing revealed that the patient possessed two heterozygous mutations (see Table 1 and Fig. 1). One was a G to A substitution at nucleotide 269 in exon 1 (c.269G > A) leading to an alteration of arginine by histidine at codon 90 (p.R90H), which had been confirmed many times [4, 5, 7, 28-32]. Another was an insertion of GG at nucleotide 1289_1290 in exon 8 (c.1289_ 1290insGG), resulting in a frameshift and a truncated protein of 466 amino acids with a premature stop codon (p.M430fsX466), which was first reported in our study. The heterozygous c.269G > A was verified in the patient's mother and the heterozygous c.1289_1290insGG in her father, suggesting that each heterozygous mutation of the patient derived from her mother and father, respectively (see Table 1 and Fig. 1).

The c.269G > A mutation is considered to be "damaging" by Polyphen-2 $(=0.992)$, LRT $(=0)$ and MutationTaster

Table 3 Sequencing outputs in patient and both parents

\begin{tabular}{llll}
\hline Individuals & Reads & Total base (Mbases) & Q30 (\%) \\
\hline Patient & $28,517,742$ & 4278 & 94.48 \\
Father & $29,321,578$ & 4398 & 94.30 \\
mother & $32,628,210$ & 4894 & 94.38 \\
\hline
\end{tabular}

prediction $(=1)$, while it is "tolerated" by SIFT $(=0.061)$. Protein domain analysis showed that URAT1 has 12 transmembrane (TM) helices, and we made a discovery that amino acid substitution p.R90H, which is located in the intracellular region close to the second TM (TM2) (Fig. 2a), is highly conserved among different species (Fig. 2b). Further, we conducted molecular modeling to predict the effect of this mutation on protein structure (Fig. 2c). In the wild model, Arg90 formed hydrogen bonds with Cys 88 and Gln93 effectively, building the conformational stability of this intracellular domain. In the mutation model, the hydrogen bond between His90 and Gln93 were weakly formed, which may decrease the stability of this domain and further affect urate transport activity. The insertion mutation c.1289_1290insGG produced a truncated protein of 466 amino acids from the position 430, with the amino acids sequence altered compared to the wild mature protein of 553 amino acids. Protein domain analysis showed that this truncated protein lacks the last three transmembrane domains, including the tripeptide motif $(\mathrm{S} / \mathrm{T}) \mathrm{X} \Phi(\mathrm{X}=$ any amino acid and $\Phi=$ hydrophobic residue) at the C-terminal, which interacts with scaffolding protein PDZK1, and together they strengthen urate transport [22].

\section{Discussion and conclusions}

Our study confirmed the comprehensive analysis of WES technology in combination with Sanger sequencing as an effective strategy to detect the causal genes and mutations in an autosomal recessive family of an RHUC daughter and healthy parents. The patient was shown to carry two heterozygous loss-of-function mutations of c.269G > A and c.1289_1290insGG, with each allele deriving from her mother and father, respectively.

Despite the well-confirmed causal genes (SLC22A12 and $S L C 2 A 9)[2,3]$ and other candidate genes related to purine metabolism/urate transport [21,33], there are still unresolved cases, which suggests still-undiscovered complicity genes and pathogenic mutations. The traditional candidate gene approach only considers a small number of genes; this strategy will fail to detect genetic variants in some patients, especially when the genetic etiology of the disease is not well known. Next-generation sequencing technologies, such as whole genome sequencing and WES, will undoubtedly detect additional genetic variants in an unbiased manner on the genome-wide level compared with traditional candidate gene sequencing. Since we sought to examine variants expected to interrupt protein function (generally located in the coding regions) with relatively lower costs, we selected WES as the prioritized method.

Until now, 31 mutations in the SLC22A12 gene (24 missense mutations [2, 4-12], 2 nonsense mutations [2, 4], 3 small deletions [4, 11, 12], 1 splice-site mutation [4], and 1 gross deletion mutation [5]) have been 


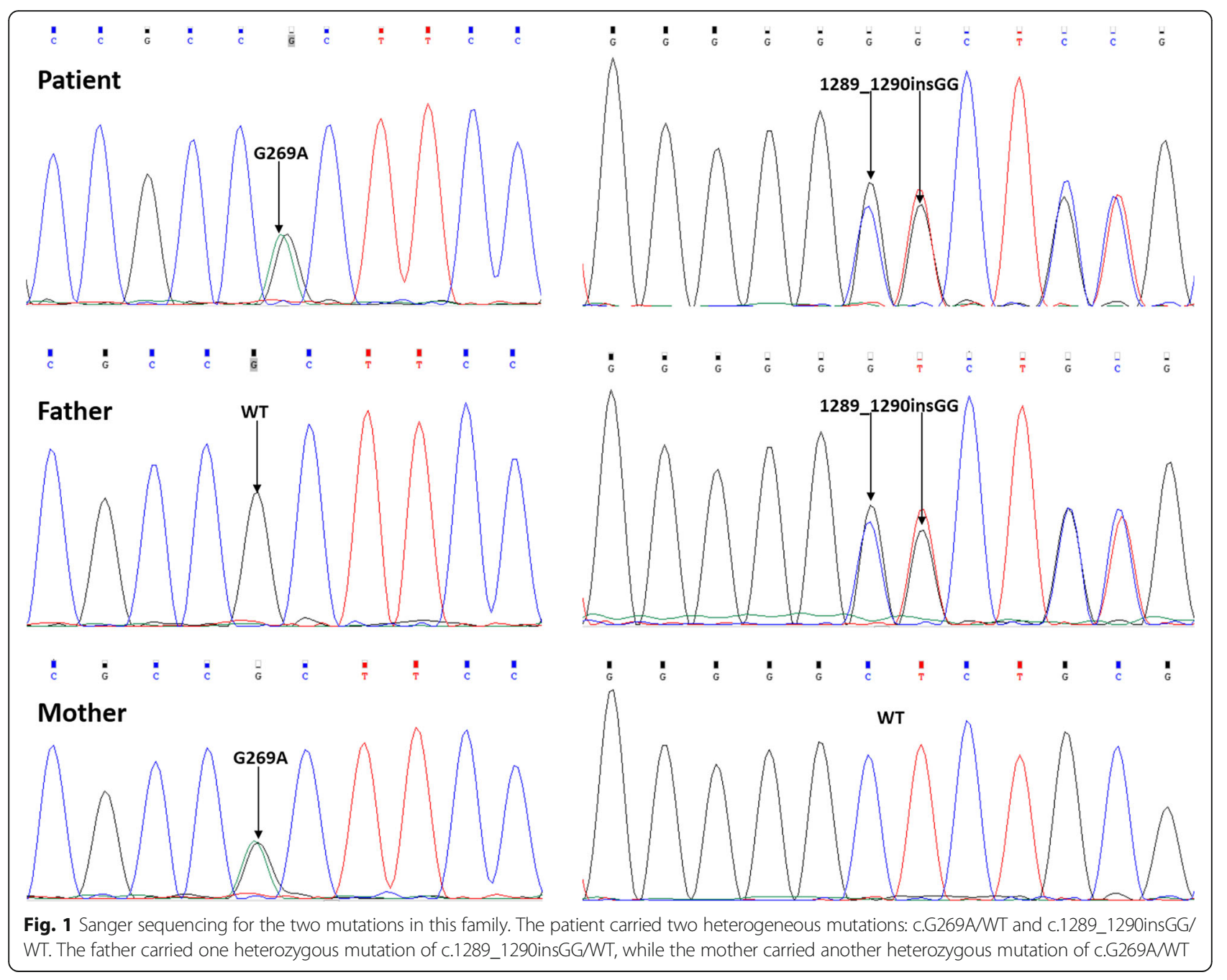

detected and functionally characterized in more than 150 RHUC patients all over the world, but most of the patients mainly live in Japan (obtained from http:// www.hgmd.cf.ac.uk/ac/all.php). Here, we summarized all of the SLC22A12 gene mutations for RHUC patients, and their clinical features in varied races were mainly obtained from typical case reports (see Table 4). Among these mutations, the W258X frequency was unexpectedly high with 184 alleles identified in 231 affected alleles (79.7\%), comparable to the single study by Ichida et al. (74.1\%) [4]. It is noteworthy that RHUC patients harboring at least one W258X mutation were more likely to be experience urolithiasis, AKI, or hematuria, with the proportion of $31.0 \%$ (36/ 116 , see Table 4). More strikingly, the ratio reached up to $44.1 \%$ in those with a homozygous mutation of W258X (30/68, see Table 4). Combined with the finding of its high frequency in the general population (2.37 and 2.24\%) $[5,34]$, we argue that the W258X mutation is the most prevalent and pathogenic in RHUC patients of Japanese origin. A similar situation occurs in Korea: the W258X allele accounted for $81.8 \%$ of all of the affected alleles (9/11, see Table 4), and severe complications were present in $66.7 \%$ of the W258X carriers $(4 / 6$, see Table 4). These results indicate that the W258X mutation possibly originated on the Asian continent. However, this mutation was not found in Chinese RHUC patients, which may be explained by the small number of reported RHUC patients in China (8 individuals, including those in the present study, see Table 4) and the consequent difficulty in detecting a specific mutation. The $\mathrm{R} 90 \mathrm{H}$ mutation ranked as the second prevalent, with the allele frequency being $7.3 \%$ $(17 / 231), 9.1 \%(1 / 11)$, and 38.5\% (5/13) in Japanese, Koreans, and Chinese with RHUC (see Table 4). Therefore, we suspect that the $\mathrm{R} 90 \mathrm{H}$ mutation may be the major contribution to Chinese RHUC patients. However, these two mutations were not found in other 

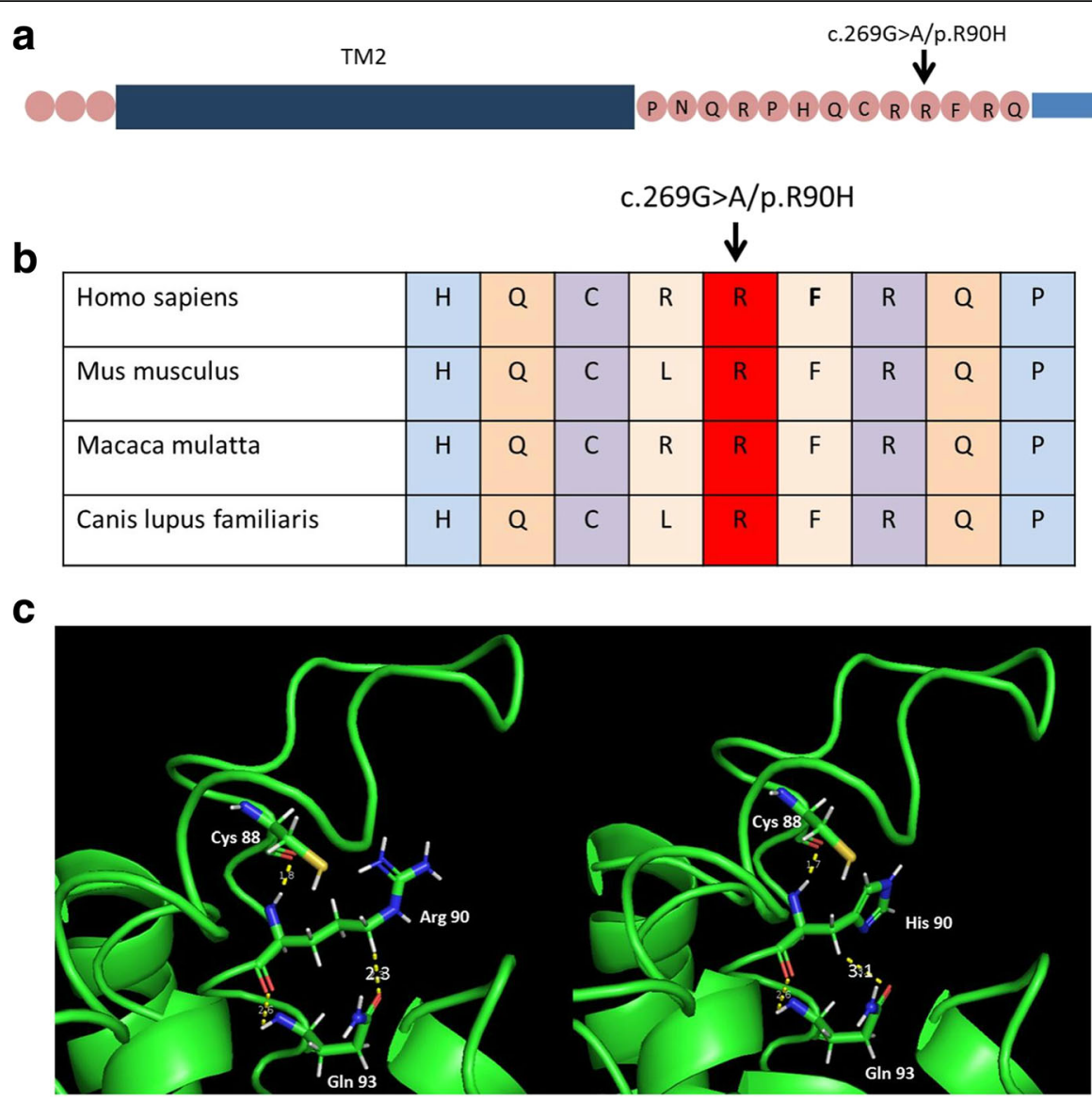

Fig. 2 c.269G > A/p.R9OH mutation identified in the RHUC patient. a This mutation is located close to the second transmembrane region (TM2) as indicated by the black arrow. $\mathbf{b}$ This identified amino acid substitution displays high evolutionary conservation among different species as indicated by the black arrow. c 3-D structures of the wild-type and c.269G > A/p.R90H URAT1 proteins with prediction software. The left shows the structure of the wild type. The right shows the structure of p.R90H. The hydrogen bond between His90 and Gln93 in the mutant is weakly formed (bond length is $3.1 \AA$ ) in comparison with the wild type (bond length is $2.3 \AA$ )

races, including Czech Roma, Iraqi Jews, and individuals of European descent (see Table 4). The L415 G417del mutation and R406C mutation were detected in most RHUC patients from the Czech Republic and Iraq, respectively (see Table 4). Recently, a molecular epidemiological study showed that the frequencies of the L415_G417del and T467 M mutations were 1.92 and $5.56 \%$, respectively, in a subgroup of the Roma population from Slovakia, the Czech Republic, and Spain [35]. Thus, we suppose each is the founder of the mutation in their respective populations. We also noted that the mutations in individuals of European descent presented with larger heterogeneity (see Table 4). On the whole, most RHUC patients were carriers of homozygous or compound heterozygous mutations (50.3\%, 87/173 and 27.2\%, 45/173, respectively; see Table 4) in the $S L C 22 A 12$ gene, which may be explained by the whole protein dysfunction. Those individuals with simple heterozygous mutations also accounted for a substantial proportion (18.5\%, 32/173) and presented with comparable clinical manifestations (see Table 4), which seemed to differ from the stereotypical interpretation that partial reservation of the normal protein may ameliorate the severity of RHUC. Considering that these patients only had one gene sequenced, the existence of additional causative genes may not be excluded, which can be corroborated by two patients with concurrent mutations in both SLC22A12 and SLC2A9 [11].

In the present study, we confirmed the presence of a heterozygous c.G269A/p.R90H mutation in the patient, and a previous functional experiment revealed that the mutation significantly decreased urate transport activity but it did not affect membrane localization [4]. In our bioinformatics analysis, the c.269G > A mutation was considered "damaging" by Polyphen-2, LRT, and MutationTaster prediction, which further corroborates its pathogenic property. Protein domain analysis showed 
Table 4 Summary of all SLC22A12 gene mutations and clinical data for RHUC patients in varied races (mainly from case reports)

\begin{tabular}{|c|c|c|c|c|c|}
\hline Races & Nucleotide change ${ }^{a}$ & Amino acid change $^{b}$ & $\begin{array}{l}\text { No. of patients } \\
\text { reported }\end{array}$ & $\begin{array}{l}\text { No. of urolithiasis, } \\
\text { AKI and hematuria }\end{array}$ & References \\
\hline \multirow[t]{21}{*}{ Japan } & G774A/G774A & W258X/W258X & 68 & $5,25,0$ & {$[2,4-7,32,36-44]$} \\
\hline & $\mathrm{G} 774 \mathrm{~A} /+$ & W258X/+ & 15 & $1,1,0$ & {$[4,6,7,29,37,44,45]$} \\
\hline & G774A/G269A & W258X/R90H & 13 & $0,0,0$ & {$[4,5,7,29,32]$} \\
\hline & G774A/1639-1643delGTCCT & W258X/frameshift & 4 & $0,0,0$ & {$[4,6,7]$} \\
\hline & G269A/G269A & $\mathrm{R} 90 \mathrm{H} / \mathrm{R} 90 \mathrm{H}$ & 1 & $0,0,0$ & {$[7]$} \\
\hline & G774A/G412A & W258XN138 M & 3 & $2,0,0$ & {$[4,7]$} \\
\hline & G774A/C650T & W258X/T217 M & 2 & $0,0,0$ & {$[4,37]$} \\
\hline & G774A/C889T & W258X/Q297X & 2 & $0,1,0$ & {$[4,32]$} \\
\hline & G774A/IVS2 + 1G > A & W258X/Frameshift & 2 & $0,0,0$ & {$[4,46]$} \\
\hline & G774A/A1145T & W258X/Q382L & 2 & $0,0,0$ & {$[4,6]$} \\
\hline & G774A/G1082 T & W258X/G361 V & 2 & $0,1,0$ & {$[7]$} \\
\hline & G269A/C889T & R90H/Q297X & 1 & $0,1,0$ & {$[31]$} \\
\hline & G269A/C1429A & $\mathrm{R} 90 \mathrm{H} / \mathrm{R} 477 \mathrm{~S}$ & 1 & $0,0,0$ & {$[7]$} \\
\hline & С650T/C650T & $\mathrm{T} 217 \mathrm{M} / \mathrm{T} 217 \mathrm{M}$ & 1 & - & {$[2]$} \\
\hline & G894 T/G894 T & E298D/E298D & 1 & - & {$[2]$} \\
\hline & C889T/IVS2 + 1G > A & Q297X/Frameshift & 1 & $0,0,0$ & {$[47]$} \\
\hline & G774A/G490A & W258X/G164S & 1 & $0,0,0$ & {$[4]$} \\
\hline & T1289C/+ & M430 T/+ & 1 & $0,0,0$ & {$[4]$} \\
\hline & 937-999del (63bp) & D313-P333del/+ & 1 & $0,0,0$ & {$[5]$} \\
\hline & G774A/T1253G & W258X/L418R & 1 & $0,0,0$ & {$[6]$} \\
\hline & G774A/G371 T & W258X/R124L & 1 & $0,0,0$ & {$[7]$} \\
\hline \multirow[t]{4}{*}{ Korea } & G774A/G774A & W258X/W258X & 3 & $1,2,0$ & {$[28,48,49]$} \\
\hline & $\mathrm{G} 774 \mathrm{~A} /+$ & W258X/+ & 2 & $0,0,1$ & {$[28]$} \\
\hline & G774A/G1430A & W258X/R477H & 1 & $0,0,1$ & {$[28]$} \\
\hline & G269A /+ & $\mathrm{R} 90 \mathrm{H} /+$ & 1 & $1,0,0$ & {$[28]$} \\
\hline \multirow[t]{6}{*}{ China } & G269A/G269A & $\mathrm{R} 90 \mathrm{H} / \mathrm{R} 90 \mathrm{H}$ & 2 & $0,1,0$ & {$[30]$} \\
\hline & 151delG/+ & A51fsX64/+ & 2 & $0,1,0$ & [11] \\
\hline & C233T/A1145T & P78L/Q382L & 1 & $0,0,1$ & {$[8]$} \\
\hline & $\begin{array}{l}\text { C650T/+, } \\
\text { SLC2A9 mut }\end{array}$ & $\begin{array}{l}\text { T217 M/+ } \\
\text { SLC2A9 mut }\end{array}$ & 1 & $0,1,0$ & {$[11]$} \\
\hline & С650T/C1546A & T217 M/P516T, SLC2A9 mut & 1 & $0,0,0$ & {$[11]$} \\
\hline & G269A/1289_1290insGG & R90H/M430fsX466 & 1 & $0,0,0$ & present study \\
\hline \multirow[t]{4}{*}{ Czech } & 1245_1253del/1245_1253del & L415_G417del/L415_G417del & 7 & - & {$[12,50]$} \\
\hline & 1245_1253del/C1400T & L415_G417del/T467 M & 4 & $0,1,0$ & {$[12,50]$} \\
\hline & С1400T/C1400T & T467 M/T467 M & 2 & $0,0,0$ & {$[50]$} \\
\hline & G1096C/G1430A & G366R/R477H & 2 & $0,0,0$ & {$[51]$} \\
\hline \multirow[t]{3}{*}{ Iraqi jews } & $\mathrm{C} 1216 \mathrm{~T} / \mathrm{C} 1216 \mathrm{~T}$ & R406C/R406C & 2 & $0,0,0$ & {$[52]$} \\
\hline & $\mathrm{C} 1216 \mathrm{~T} /+$ & R406C/+ & 2 & $0,0,0$ & {$[52]$} \\
\hline & C1216T/+; G1330A/G1330A & R406C/+; G444R/G444R & 2 & $1,0,0$ & {$[52]$} \\
\hline Israel-Arab & $+/+$ & $+/+$ & 4 & $0,2,0$ & {$[25]$} \\
\hline Italy & $+/+$ & $+/+$ & 1 & $0,1,0$ & {$[24]$} \\
\hline \multirow{3}{*}{$\begin{array}{l}\text { Macedonian } \\
\text { and British }\end{array}$} & C1300T/+ & R434C/+ & 3 & $1,0,0$ & {$[9]$} \\
\hline & $\mathrm{G} 1301 \mathrm{~A} /+$ & $\mathrm{R} 434 \mathrm{H} /+$ & 2 & $0,0,0$ & {$[9]$} \\
\hline & $\mathrm{C} 1039 \mathrm{~A} /+$ & R347S/+ & 1 & $0,0,1$ & [9] \\
\hline
\end{tabular}


Table 4 Summary of all SLC22A12 gene mutations and clinical data for RHUC patients in varied races (mainly from case reports) (Continued)

\begin{tabular}{|c|c|c|c|c|c|}
\hline Races & Nucleotide change $^{a}$ & Amino acid change & $\begin{array}{l}\text { No. of patients } \\
\text { reported }\end{array}$ & $\begin{array}{l}\text { No. of urolithiasis, } \\
\text { AKI and hematuria }\end{array}$ & References \\
\hline & $\mathrm{G} 1162 \mathrm{~A} /+$ & V388 M/+ & 1 & $1,0,0$ & [9] \\
\hline & $\mathrm{T} 224 \mathrm{C} /+$ & $175 T /+$ & 1 & $1,0,0$ & [9] \\
\hline African Americans & G193 T & G65 W & - & - & {$[10]$} \\
\hline
\end{tabular}

+ indicates the wild-type allele. Note: G65 W was identified to be associated with lower SUA level by GWAS, not case reports

according to coding sequence

baccording to amino acid

that URAT1 has 12 TM helices, and we made a discovery that amino acid substitution p.R90H, which is located close to the second TM (TM2), is highly conserved among different species, suggesting the probable functional significance for urate transport. Further, we conducted the molecular modeling to predict the effect of this mutation on protein structure. In the wild model, Arg90 formed hydrogen bonds with Cys88 and Gln93 effectively, building the conformational stability of this intracellular domain. In the mutation model, the hydrogen bond between His90 and Gln93 were weakly formed, which may decrease the stability of this domain and further affect urate transport activity. Of course, this effect may also not be strong enough to impair the domain's stability. Instead, His90 per se has fewer hydrogen atoms, which can form hydrogen bonds, and thus it may impair the coupling between URAT1 and other unknown proteins that together participate in urate transport. This mutation was identified in the Exome Sequencing Project with the frequency of $7.70^{*} 10^{-5}$, but it was not found in 1000 Genomes. In a recent study from Japan, the prevalence of p.R90H was found to be $0.28 \%$ in healthy examined participants and these subjects showed a marked decrease of SUA level [34]. All of these materials confirm that this mutation is not prevalent in the general population and it is responsible for protein malfunction. We also detected a novel heterozygous mutation of c.1289_1290insGG that resulted in a truncated protein of 466 amino acids from the position 430 (p.M430fsX466), with the amino acid sequence altered compared to the wild mature protein of 553 amino acids. Protein domain analysis showed that this truncated protein lacks the last three transmembrane domains, including the tripeptide motif $(\mathrm{S} / \mathrm{T}) \mathrm{X} \Phi(\mathrm{X}=$ any amino acid and $\Phi=$ hydrophobic residue) at the Cterminal, which interacts with scaffolding protein PDZK1, and together they strengthen the urate transport [22]. Thus, the p.M430fsX466 mutation will possibly lead to weak functioning of urate transport through the disruption of the "transporter complex" formed by URAT1 and PDZK1. This mutation was not identified in either the Exome Sequencing Project or 1000 Genomes, which strengthens the suspected pathogenicity. Taken together, we considered that this patient with such compound heterozygous mutations presents whole functional defects of URAT1 and deficiency of UA reabsorption. Next, we summarized all of the mutations' frequencies in some opensource databases and bioinformatics prediction results for mutation pathogenicity (see Table 5). All of the mutations were at a very low frequency or not found in the present databases, with most predicted to be damaging or possibly damaging. Combined with our protein analysis for $\mathrm{R} 90 \mathrm{H}$ and M430fsX466 mentioned above, we concluded that mutation-induced structural instability or malfunction of the urate transporter complex may be the main mechanisms for this hereditary disorder.

Generally, most RHUC patients are asymptomatic with no manifestations of urolithiasis and AKI [1], as with our patient. An inquiry of the patient's medical history revealed that the woman was a vegetarian who did not favor meat, which contains more purine. Thus, the amount of urate excreted into urine was within the normal range, even if the FEUA was increased, which might explain why our patient was asymptomatic. Treatment is unavailable and outcomes may be severe. So, it is still necessary for the patient to follow the medical orders prescribed by clinicians to prevent the incidence of adverse events. Considering that the offspring of this patient will carry at least one heterozygous mutation and that potential mutations may be located in any of the exons of the SLC22A12 gene (see Table 5), we recommend the patient's future husband undergo whole gene sequencing for at least the $S L C 22 A 12$ gene, and try to exclude mutant carriers to minimize the risk of severe hyperuricemia in the patient's offspring.

This study had some limitations. We applied WES to scan the potential variants for the disease, but in each filtering step of the prioritization protocol, there was inevitable bias, which might produce inconsistent results in our validation of the subsequent Sanger sequencing. We analyzed a single patient and our results may not represent the general genetic etiology for Chinese patients with RHUC. In the future, we should conduct a large-scale epidemiological 
Table 5 Mutation frequency and pathogenicity prediction for all SLC22A12 mutations

\begin{tabular}{|c|c|c|c|c|c|c|c|c|c|}
\hline \multirow{2}{*}{$\begin{array}{l}\text { Nucleotide } \\
\text { change }^{a}\end{array}$} & \multirow{2}{*}{$\begin{array}{l}\text { Amino acid } \\
\text { change }^{b}\end{array}$} & \multirow{2}{*}{$\begin{array}{l}\text { Start position } \\
\text { (GRCh37.p13 } \\
\text { Primary } \\
\text { Assembly) }\end{array}$} & \multicolumn{3}{|l|}{ Mutation frequency } & \multicolumn{4}{|c|}{ Bioinformatics analysis results } \\
\hline & & & $\overline{\text { 1000g2015aug_all }}$ & EXAC & esp6500siv2_all & $\overline{\mathrm{SIFT}}$ & Polyphen-2 & LRT & MutationTaster \\
\hline 151delG & A51fsX64: & Chr11; 64,359,179 & . & . & . & . & . & . & \\
\hline G193 T & G65 W & Chr11; 64,359,221 & & . & . & $\mathrm{D}$ & $\mathrm{D}$ & $\mathrm{N}$ & N \\
\hline $\mathrm{T} 224 \mathrm{C}$ & $175 T$ & Chr11; 64,359,252 & 0.0002 & 0.0002 & 0.0005 & $\mathrm{D}$ & D & $\mathrm{N}$ & N \\
\hline $\mathrm{C} 233 \mathrm{~T}$ & P78L & Chr11; 64,359,261 & . & $2.51 * 10^{-5}$ & & $\mathrm{D}$ & $\mathrm{D}$ & $\mathrm{D}$ & $\mathrm{D}$ \\
\hline G269A & $\mathrm{R} 90 \mathrm{H}$ & Chr11; 64,359,297 & & 0.0002 & $7.70^{*} 10^{-5}$ & $\mathrm{~T}$ & D & $\mathrm{D}$ & A \\
\hline G371 T & R124L & Chr11; 64,359,399 & . & . & & $\mathrm{T}$ & $P$ & $\mathrm{~N}$ & $\mathrm{~N}$ \\
\hline G412A & V138 M & Chr11; 64,360,260 & & $6.59^{*} 10^{-5}$ & . & D & D & D & D \\
\hline G490A & G164S & Chr11; 64,360,338 & . & 0.0001 & . & $\mathrm{D}$ & D & $\mathrm{N}$ & $\mathrm{N}$ \\
\hline $\mathrm{IVS} 2+1 \mathrm{G}>\mathrm{A}$ & Frameshift & Chr11; 64,360,355 & 0.0002 & $2.48^{*} 10^{-5}$ & . & . & . & . & D \\
\hline С650T & $\mathrm{T} 217 \mathrm{M}$ & Chr11; 64,361,020 & . & $3.31 * 10^{-5}$ & & D & D & $\mathrm{N}$ & A \\
\hline G774A & W258X & Chr11; 64,361,219 & 0.000998 & 0.0003 & . & . & . & $\mathrm{D}$ & A \\
\hline С889T & Q297X & Chr11; 64,366,046 & . & . & . & . & & $\mathrm{N}$ & A \\
\hline G894 T & E298D & Chr11; 64,366,051 & . & . & . & $\mathrm{T}$ & D & $\mathrm{D}$ & A \\
\hline $\begin{array}{l}937 \text { 999del } \\
(63 \mathrm{bp})\end{array}$ & D313_P333del & Chr11; 64,366,094 & & . & . & . & . & . & . \\
\hline C1039A & R347S & Chr11; 64,366,364 & 0.0002 & . & . & $\mathrm{T}$ & D & $\mathrm{D}$ & D \\
\hline G1082 T & G361 V & Chr11; 64,367,159 & & . & . & $\mathrm{T}$ & D & D & A \\
\hline G1096C & G366R & Chr11; 64,367,173 & . & . & . & $\mathrm{D}$ & D & $\mathrm{D}$ & D \\
\hline A1145T & Q382L & Chr11; 64,367,222 & & $6.72 * 10^{-5}$ & . & D & D & $\mathrm{D}$ & D \\
\hline G1162A & V388 M & Chr11; 64,367,239 & . & 0.0002 & $7.70^{*} 10^{-5}$ & $\mathrm{~T}$ & D & N & N \\
\hline $\mathrm{C} 1216 \mathrm{~T}$ & R406C & Chr11; 64,367,293 & . & $4.23^{*} 10^{-5}$ & . & D & D & D & D \\
\hline 1245_1253del & L415_G417del & Chr11; 64,367,322 & . & . & . & . & & . & . \\
\hline T1253G & L418R & Chr11; 64,367,330 & . & $1.73 * 10^{-5}$ & . & D & D & N & A \\
\hline $\mathrm{T} 1289 \mathrm{C}$ & M430 T & Chr11; 64,367,842 & . & . & . & $\mathrm{T}$ & $P$ & $\mathrm{~N}$ & D \\
\hline 1289_1290insGG & M430fsX466 & Chr11; 64,367,842 & . & . & . & . & . & . & . \\
\hline С1300T & R434C & Chr11; 64,367,853 & . & 0.0002 & $7.70^{*} 10^{-5}$ & $\mathrm{~T}$ & $\mathrm{P}$ & N & D \\
\hline G1301A & $\mathrm{R} 434 \mathrm{H}$ & Chr11; 64,367,854 & 0.004593 & 0.0025 & 0.0049 & D & D & $\mathrm{D}$ & D \\
\hline G1330A & G444R & Chr11; 64,367,883 & . & $6.07^{*} 10^{-5}$ & & $\mathrm{~T}$ & D & $\mathrm{N}$ & N \\
\hline C1400T & T467 M & Chr11; 64,368,212 & 0.001797 & 0.0014 & $7.70^{*} 10^{-5}$ & $\mathrm{~T}$ & D & N & N \\
\hline C1429A & R477S & Chr11; 64,368,241 & . & . & & D & D & $\mathrm{D}$ & D \\
\hline G1430A & $\mathrm{R} 477 \mathrm{H}$ & Chr11; 64,368,242 & & $9.22^{*} 10^{-5}$ & . & D & D & D & D \\
\hline C1546A & P516T & Chr11; 64,368,358 & . & . & . & $\mathrm{D}$ & D & $\mathrm{D}$ & D \\
\hline 1639_1643del & Frameshift & Chr11; 64,369,000 & & & . & . & . & & . \\
\hline
\end{tabular}

SIFT: D means deleterious, T means tolerated; Polyphen-2: D means probably damaging, P means possibly damaging; LRT: D means deleterious, $\mathrm{N}$ means neutral, $\mathrm{U}$ means unknown; MutationTaster: A means disease_causing_automatic, D means disease_causing, $\mathrm{N}$ means polymorphism. Dot means not found or unknown according to coding sequence

baccording to amino acid

* means multiplication sign

survey in the general population to identify the overall RHUC prevalence in the Chinese population to obtain a full picture regarding the genetic aberrance for this disorder.

In conclusion, we successfully established a Chinese RHUC patient caused by novel compound heterozygous mutations of the SLC22A12 gene using WES and Sanger sequencing for the first time. As WES is less expensive than traditional methods and more patients are willing to undergo genetic testing, we will acquire a comprehensive mutational landscape for this hereditary disease and further develop specific diagnostic kits for genetic counseling and diagnosis. 


\section{Additional file}

Additional file 1: The putative genetic mutations in WES analysis. According to an assumed inheritance of autosomal recessive mode for this disease, we first analyzed the putative genetic mutations homozygous in the patient and heterozygous in both parents. After filtering, 29 variants were retained (see Sheet 1). We also analyzed the putative causal mutations present in the patient but not present in her parents. After filtering, a total of 521 suspicious mutations were screened out (see Sheet 2). (XLSX 298 kb)

\section{Abbreviations}

AKI: Acute kidney injury; BWA: Burrows-Wheeler Aligner; FEUA: Fractional excretion of uric acid; GATK: Genome analysis toolkit; GLUT9: Glucose transporter member 9; GWAS: Genome-wide association studies; LMPCR: Ligation-mediated polymerase chain reaction; PDZK1: PDZ domain containing 1; RHUC: Renal hypouricemia; SUA: Serum uric acid concentration; TM: Transmembrane; URAT1: Uric acid transporter 1

\section{Acknowledgements}

We appreciate the voluntary participation of all subjects.

\section{Ethics approval and consent to participant}

The study was approved by the Ethics Committee of Shanghai Jiao Tong University and the Affiliated Hospital of Qingdao University, and in accordance with the principles of the Declaration of Helsinki. All participants gave their written informed consent to take part in the present study.

\section{Funding}

This work was supported by the 973 Program (2015CB559100), the National Key R\&D Program of China (2016YFC0903401, 2016YFC0903402, 2016YFC1306903, 2016YFC0902403, 2017YFC0908105), the Natural Science Foundation of China $(81770869,31371272,81520108007,81421061,81701321,31325014,81130022$ $21375139,31571012$ and 81501154$)$, the Program of Shanghai Subject Chief Scientist (15XD1502200), the National Program for Support of Top-Notch Young Professionals, Shanghai Key Laboratory of Psychotic Disorders (13dz2260500), the 'Shu Guang' project supported by the Shanghai Municipal Education Commission and Shanghai Education Development Foundation (12SG17), the China Postdoctoral Science Foundation (2016 M590615), the Shandong Postdoctoral Innovation Foundation (201601015), the Qingdao Postdoctoral Application Research Project (2016048), the Shanghai Jiao Tong Univ Liberal Arts and Sciences Cross-Disciplinary Project (13JCRZ02), Shanghai Hospital Development Center (SHDC12016115), Shanghai Mental Health Center (2016-fx-02).

\section{Availability of data and materials}

The datasets used and analyzed during the current study are available from the corresponding author on reasonable request.

\section{Authors' contributions}

SYY and LCG conceived and supervised the entire project. ZZW and MLD are first co-authors contributing equally to this work. ZZW engaged in the entire experiment procedure and composed the article. MLD was the primary care physician of this patient and prepared the DNA sample. ZJ and CBY participated in the sequencing. SZJ and WK participated in sequencing data analysis. LZQ participated in data interpretation. ZJM and PD assisted in protein structure analysis. All authors have read and approved the manuscript.

\section{Consent for publication}

This family have given their written consents for the case report to be published.

\section{Competing interests}

The authors declare that they have no competing interests.

\section{Publisher's Note}

Springer Nature remains neutral with regard to jurisdictional claims in published maps and institutional affiliations.

\section{Author details}

Bio-X Institutes, Key Laboratory for the Genetics of Developmental and Neuropsychiatric Disorders (Ministry of Education), Shanghai Jiao Tong University, No. 1954 Huashan Road, Shanghai 200030, People's Republic of China. ${ }^{2}$ Shandong Gout Clinical Medical Center, Qingdao 266003, People's Republic of China. ${ }^{3}$ Shandong Provincial Key Laboratory of Metabolic Disease, The Affiliated Hospital of Qingdao University, No. 16 Jiangsu Road, Qingdao 266003, People's Republic of China. ${ }^{4}$ The Department of Endocrinology and Metabolism, The Affiliated Hospital of Qingdao University, Qingdao 266003, People's Republic of China. ${ }^{5}$ Biomedical Sciences Institute, the Qingdao Branch of SJTU Bio-X Institutes, Qingdao University, Qingdao 266003, People's Republic of China. ${ }^{6}$ Metabolic Disease Institute, Qingdao University, Qingdao 266003, People's Republic of China.

Received: 15 January 2018 Accepted: 26 April 2018

Published online: 10 August 2018

\section{References}

1. Sperling O. Renal hypouricemia: classification, tubular defect and clinical consequences. Contrib Nephrol. 1992;100:1-14.

2. Enomoto A, Kimura H, Chairoungdua A, Shigeta $Y$, Jutabha $P$, Cha SH, Hosoyamada M, Takeda M, Sekine T, Igarashi T, et al. Molecular identification of a renal urate anion exchanger that regulates blood urate levels. Nature. 2002:417(6887):447-52.

3. Anzai N, Ichida K, Jutabha P, Kimura T, Babu E, Jin CJ, Srivastava S, Kitamura $\mathrm{K}$, Hisatome I, Endou $\mathrm{H}$, et al. Plasma urate level is directly regulated by a voltage-driven urate efflux transporter URATV1 (SLC2A9) in humans. J Biol Chem. 2008;283(40):26834-8.

4. Ichida K, Hosoyamada M, Hisatome I, Enomoto A, Hikita M, Endou H, Hosoya T. Clinical and molecular analysis of patients with renal hypouricemia in Japan-influence of URAT1 gene on urinary urate excretion. J Am Soc Nephrol. 2004;15(1):164-73.

5. Iwai N, Mino Y, Hosoyamada M, Tago N, Kokubo Y, Endou H. A high prevalence of renal hypouricemia caused by inactive SLC22A12 in Japanese. Kidney Int. 2004:66(3):935-44.

6. Wakida N, Tuyen DG, Adachi M, Miyoshi T, Nonoguchi H, Oka T, Ueda O, Tazawa M, Kurihara S, Yoneta Y, et al. Mutations in human urate transporter 1 gene in presecretory reabsorption defect type of familial renal hypouricemia. J Clin Endocrinol Metab. 2005;90(4):2169-74.

7. Ichida K, Hosoyamada M, Kamatani N, Kamitsuji S, Hisatome I, Shibasaki T, Hosoya T. Age and origin of the G774A mutation in SLC22A12 causing renal hypouricemia in Japanese. Clin Genet. 2008;74(3):243-51.

8. Lam CW, Kong AP, Tsui TK, Ozaki R, Chan HM, Tong SF, Siu TS, Tam S, Chan JC. A novel mutation of SLC22A12 gene causing primary renal hypouricemia in a patient with metabolic syndrome. Clin Chim Acta. 2008; 398(1-2):157-8

9. Tasic V, Hynes AM, Kitamura K, Cheong HI, Lozanovski VJ, Gucev Z, Jutabha $P$, Anzai N, Sayer JA. Clinical and functional characterization of URAT1 variants. PLoS One. 2011;6(12):e28641.

10. Tin A, Woodward OM, Kao WH, Liu CT, Lu X, Nalls MA, Shriner D, Semmo M, Akylbekova EL, Wyatt SB, et al. Genome-wide association study for serum urate concentrations and gout among African Americans identifies genomic risk loci and a novel URAT1 loss-of-function allele. Hum Mol Genet. 2011; 20(20):4056-68.

11. Li Z, Ding $H$, Chen $C$, Chen Y, Wang DW, LV Y. Novel URAT1 mutations caused acute renal failure after exercise in two Chinese families with renal hypouricemia. Gene. 2013;512(1):97-101.

12. Stiburkova B, Sebesta I, Ichida K, Nakamura M, Hulkova H, Krylov V, Kryspinova L, Jahnova $\mathrm{H}$. Novel allelic variants and evidence for a prevalent mutation in URAT1 causing renal hypouricemia: biochemical, genetics and functional analysis. Eur J Hum Genet. 2013;21(10):1067-73.

13. Doring A, Gieger C, Mehta D, Gohlke H, Prokisch H, Coassin S, Fischer G, Henke K, Klopp N, Kronenberg F, et al. SLC2A9 influences uric acid concentrations with pronounced sex-specific effects. Nat Genet. 2008;40(4):430-6.

14. Vitart V, Rudan I, Hayward C, Gray NK, Floyd J, Palmer CN, Knott SA, Kolcic I, Polasek O, Graessler J, et al. SLC2A9 is a newly identified urate transporter influencing serum urate concentration, urate excretion and gout. Nat Genet. 2008:40(4):437-42

15. Li S, Sanna S, Maschio A, Busonero F, Usala G, Mulas A, Lai S, Dei M, Orru M, Albai G, et al. The GLUT9 gene is associated with serum uric acid levels in Sardinia and chianti cohorts. PLoS Genet. 2007;3(11):e194 
16. McArdle PF, Parsa A, Chang YP, Weir MR, O'Connell JR, Mitchell BD, Shuldiner AR. Association of a common nonsynonymous variant in GLUT9 with serum uric acid levels in old order amish. Arthritis Rheum. 2008;58(9): 2874-81.

17. Voruganti VS, Kent JW Jr, Debnath S, Cole SA, Haack K, Goring HH, Carless MA, Curran JE, Johnson MP, Almasy L, et al. Genome-wide association analysis confirms and extends the association of SLC2A9 with serum uric acid levels to Mexican Americans. Front Genet. 2013;4:279.

18. Kolz M, Johnson T, Sanna S, Teumer A, Vitart V, Perola M, Mangino M, Albrecht E, Wallace C, Farrall M, et al. Meta-analysis of 28,141 individuals identifies common variants within five new loci that influence uric acid concentrations. PLoS Genet. 2009;5(6):e1000504.

19. Kamatani Y, Matsuda K, Okada Y, Kubo M, Hosono N, Daigo Y, Nakamura Y, Kamatani N. Genome-wide association study of hematological and biochemical traits in a Japanese population. Nat Genet. 2010;42(3):210-5.

20. Kottgen A, Albrecht E, Teumer A, Vitart V, Krumsiek J, Hundertmark C, Pistis G, Ruggiero D, O'Seaghdha CM, Haller T, et al. Genome-wide association analyses identify 18 new loci associated with serum urate concentrations. Nat Genet. 2013;45(2):145-54.

21. Mandal AK, Mount DB. The molecular physiology of uric acid homeostasis. Annu Rev Physiol. 2015;77:323-45.

22. Anzai N, Miyazaki H, Noshiro R, Khamdang S, Chairoungdua A, Shin HJ, Enomoto A, Sakamoto S, Hirata T, Tomita K, et al. The multivalent PDZ domain-containing protein $\mathrm{PDZK} 1$ regulates transport activity of renal urate-anion exchanger URAT1 via its C terminus. J Biol Chem. 2004; 279(44):45942-50.

23. Gisler SM, Pribanic S, Bacic D, Forrer P, Gantenbein A, Sabourin LA, Tsuji A, Zhao ZS, Manser E, Biber J, et al. PDZK1: I. A major scaffolder in brush borders of proximal tubular cells. Kidney Int. 2003;64(5):1733-45.

24. Ouellet G, Lin SH, Nolin L, Bonnardeaux A. Hereditary renal hypouricemia in a Caucasian patient: a case report and review of the literature. Nephrol Ther 2009:5(6):568-71.

25. Bahat H, Dinour D, Ganon L, Feldman L, Holtzman EJ, Goldman M. Nonurate transporter 1-related renal hypouricemia and acute renal failure in an Israeli-Arab family. Pediatr Nephrol. 2009;24(5):999-1003.

26. Bhasin B, Stiburkova B, De Castro-Pretelt M, Beck N, Bodurtha JN, Atta MG. Hereditary renal hypouricemia: a new role for allopurinol? Am J Med. 2014; 127(1):e3-4.

27. Wang K, Li M, Hakonarson H. ANNOVAR: functional annotation of genetic variants from high-throughput sequencing data. Nucleic Acids Res. 2010; 38(16):e164

28. Cheong HI, Kang JH, Lee $\mathrm{JH}, \mathrm{Ha}$ IS, Kim S, Komoda F, Sekine T, Igarashi T, Choi Y. Mutational analysis of idiopathic renal hypouricemia in Korea. Pediatr Nephrol. 2005;20(7):886-90.

29. Komatsuda A, Iwamoto K, Wakui H, Sawada K, Yamaguchi A. Analysis of mutations in the urate transporter 1 (URAT1) gene of Japanese patients with hypouricemia in northern Japan and review of the literature. Ren Fail. 2006;28(3):223-7.

30. Yan MT, Cheng CJ, Chen JS, Lin SH. The case: a young man with acute kidney injury after exercise. The diagnosis: exercise induced acute kidney injury in hereditary renal hypouricemia. Kidney Int. 2010;77(10):935-6.

31. Ochi A, Takei T, Ichikawa A, Kojima C, Moriyama T, Itabashi M, Mochizuki T, Taniguchi A, Nitta K. A case of acute renal failure after exercise with renal hypouricemia demonstrated compound heterozygous mutations of uric acid transporter 1. Clin Exp Nephrol. 2012;16(2):316-9.

32. Kaito H, Ishimori S, Nozu K, Shima Y, Nakanishi K, Yoshikawa N, lijima K. Molecular background of urate transporter genes in patients with exerciseinduced acute kidney injury. Am J Nephrol. 2013;38(4):316-20.

33. Anzai $N$, Kanai $Y$, Endou $H$. New insights into renal transport of urate. Curr Opin Rheumatol. 2007;19(2):151-7.

34. Sakiyama M, Matsuo H, Shimizu S, Nakashima H, Nakamura T, Nakayama A, Higashino T, Naito M, Suma S, Hishida A, et al. The effects of URAT1/ SLC22A12 nonfunctional variants, R90H and W258X, on serum uric acid levels and gout/hyperuricemia progression. Sci Rep. 2016;6:20148.

35. Stiburkova B, Gabrikova D, Cepek P, Simek P, Kristian P, Cordoba-Lanus E, Claverie-Martin F. Prevalence of URAT1 allelic variants in the Roma population. Nucleotides Nucleic Acids. 2016;35(10-12):529-35.

36. Tanaka M, Itoh K, Matsushita K, Matsushita K, Wakita N, Adachi M, Nonoguchi H, Kitamura K, Hosoyamada M, Endou H, et al. Two male siblings with hereditary renal hypouricemia and exercise-induced ARF. Am J Kidney Dis. 2003;42(6):1287-92.
37. Komoda F, Sekine T, Inatomi J, Enomoto A, Endou H, Ota T, Matsuyama T, Ogata T, Ikeda M, Awazu M, et al. The W258X mutation in SLC22A12 is the predominant cause of Japanese renal hypouricemia. Pediatr Nephrol. 2004; 19(7):728-33.

38. Yamamoto I, Yamamoto H, Ichida K, Mitome J, Tanno Y, Katoh N, Yokoyama K, Hosoya T. Successful living-related kidney transplantation in hereditary renal hypouricaemia. Nephrol Dial Transplant. 2006;21(7):2041.

39. Ohtsuka Y, Zaitsu M, Ichida K, Isomura N, Tsuji K, Sato T, Hamasaki Y. Human uric acid transporter 1 gene analysis in familial renal hypo-uricemia associated with exercise-induced acute renal failure. Pediatr Int. 2007;49(2):235-7.

40. Mima A, Ichida K, Matsubara T, Kanamori H, Inui E, Tanaka M, Manabe $Y$, lehara N, Tanaka Y, Yanagita M, et al. Acute renal failure after exercise in a Japanese sumo wrestler with renal hypouricemia. Am J Med Sci. 2008; 336(6):512-4.

41. Takeda Y, Abe A, Nakanishi S, Umezu M, Hirano K, Hayakawa H, Ohno I, Ichida K, Yamaguchi Y, Hosoya T, et al. Two cases of nephrotic syndrome (NS)-induced acute kidney injury (AKI) associated with renal hypouricemia. Clin Nephrol. 2011;76(1):78-82.

42. Nishizaki N, Fujinaga S, Hirano D, Kanai H, Kaya H, Ohtomo Y, Shimizu T, Nozu K, Kaneko K. Hereditary renal hypouricemia: a cause of calcium oxalate urolithiasis in a young female. Clin Nephrol. 2012;77(2):161-3.

43. Fujinaga S, Ito A, Nakagawa M, Watanabe T, Ohtomo Y, Shimizu T. Posterior reversible encephalopathy syndrome with exercise-induced acute kidney injury in renal hypouricemia type 1. Eur J Pediatr. 2013;172(11):1557-60.

44. Kamei K, Ogura M, Ishimori S, Kaito H, lijima K, Ito S. Acute kidney injury after acute gastroenteritis in an infant with hereditary hypouricemia. Eur J Pediatr. 2014;173(2):247-9.

45. Mitani N, Niwa Y, Yamazaki M, Okamoto Y. Genetic analysis of idiopathic renal hypouricemia: a case report and estimation of allelic frequency of the mutation. Rinsho Byori. 2006;54(6):589-92

46. Inazu T. A case of renal hypouricemia caused by urate transporter 1 gene mutations. Clin Nephrol. 2006;65(5):370-3.

47. Takahashi T, Tsuchida S, Oyamada T, Ohno T, Miyashita M, Saito S, Komatsu K, Takashina K, Takada G. Recurrent URAT1 gene mutations and prevalence of renal hypouricemia in Japanese. Pediatr Nephrol. 2005;20(5):576-8.

48. Kim YH, Cho JT. A case of exercise-induced acute renal failure with G774A mutation in SCL22A12 causing renal hypouricemia. J Korean Med Sci. 2011; 26(9):1238-40

49. Kim HO, Ihm CG, Jeong KH, Kang HJ, Kim JM, Lim HS, Kim JS, Lee TW. A case report of familial renal Hypouricemia confirmed by genotyping of SLC22A12, and a literature review. Electrolyte Blood Press. 2015;13(2):52-7.

50. Gabrikova D, Bernasovska J, Sokolova J, Stiburkova B. High frequency of SLC22A12 variants causing renal hypouricemia 1 in the Czech and Slovak Roma population; simple and rapid detection method by allele-specific polymerase chain reaction. Urolithiasis. 2015;43(5):441-5.

51. Stiburkova B, Stekrova J, Nakamura M, Ichida K. Hereditary renal Hypouricemia type 1 and autosomal dominant polycystic kidney disease. Am J Med Sci. 2015:350(4):268-71.

52. Dinour D, Bahn A, Ganon L, Ron R, Geifman-Holtzman O, Knecht A, Gafter U, Rachamimov R, Sela BA, Burckhardt G, et al. URAT1 mutations cause renal hypouricemia type 1 in Iraqi Jews. Nephrol Dial Transplant. 2011;26(7):2175-81.

\section{Ready to submit your research? Choose BMC and benefit from:}

- fast, convenient online submission

- thorough peer review by experienced researchers in your field

- rapid publication on acceptance

- support for research data, including large and complex data types

- gold Open Access which fosters wider collaboration and increased citations

- maximum visibility for your research: over $100 \mathrm{M}$ website views per year

At BMC, research is always in progress.

Learn more biomedcentral.com/submissions 